\title{
Effect of Nutrition Education Based on Health Belief Model on Nutritional Knowledge and Dietary Practice of Pregnant Women in Dessie Town, Northeast Ethiopia: A Cluster Randomized Control Trial
}

\author{
Tona Zema Diddana $\left(\mathbb{D},{ }^{1}\right.$ Gezahegn Nigusse Kelkay, ${ }^{1}$ Amanuel Nana Dola $\left(\mathbb{D},{ }^{2}\right.$ \\ and Abinet Arega Sadore ${ }^{3}$ \\ ${ }^{1}$ School of Nutrition, Food Science and Technology, Hawassa University, Hawassa, Ethiopia \\ ${ }^{2}$ Faculty of Chemical and Food Engineering, Bahir Dar Institute of Technology, Bahir Dar, Ethiopia \\ ${ }^{3}$ School of Public Health, Jimma University, Jimma, Ethiopia \\ Correspondence should be addressed to Tona Zema Diddana; tonazema@gmail.com
}

Received 29 January 2018; Revised 2 April 2018; Accepted 21 May 2018; Published 21 June 2018

Academic Editor: C. S. Johnston

Copyright ( $\odot 2018$ Tona Zema Diddana et al. This is an open access article distributed under the Creative Commons Attribution License, which permits unrestricted use, distribution, and reproduction in any medium, provided the original work is properly cited.

\begin{abstract}
Background. In Ethiopia, poor dietary practice among pregnant women ranges from 39.3 to $66.1 \%$. Limited nutritional knowledge and wrong perception towards dietary behaviours were underlying factors. Hence, this study was aimed to determine the effect of nutrition education based on Health Belief Model on nutritional knowledge and dietary practice of pregnant women in Dissie town, northeast Ethiopia, 2017 GC. Methods. Community-based cluster randomized control trial was employed. A total of 138 pregnant women participated. Nutrition education was given using Health Belief Model (HBM) theory and general nutrition education for intervention and control group, respectively. The baseline and endline nutrition knowledge and dietary practice was assessed using knowledge and dietary practice questions. HBM construct was assessed using five-point likert scale. Data were analyzed using SPSS version 20. Student's $t$-tests and chi-square tests were used. At $95 \%$ confidence level, $P<0.05$ was considered statistically significant. Result. The mean pre- and postintervention nutritional knowledge was 6.9 and 13.4, and good dietary practice was $56.5 \%$ and $84.1 \%$ in intervention group, respectively. The increase in mean nutritional knowledge was statistically significant $(P<0.001)$. In control group, the pre- and postintervention mean nutritional knowledge was 7.4 and 9.8 , and good dietary practice was $60.9 \%$ and $72.5 \%$, respectively. There was significant difference $(P<0.05)$ in mean nutritional knowledge and proportion of good dietary practices between two groups at endline, but the difference was not significant $(P>0.05)$ at baseline. There was significant $(P<0.001)$ improvement in the scores of HBM constructs in intervention group. Conclusion and Recommendations. Providing nutrition education based on Health Belief Model improves nutritional knowledge and dietary practices of pregnant women. Hence, governmental, nongovernmental organization, health extension workers, and other health-care provider should include Health Belief Model construct into existing nutrition education programs. Moreover, government should incorporate HBM theory into national nutrition education guidelines.
\end{abstract}

\section{Introduction}

Pregnancy is the most crucial nutritionally demanding period of every woman's life. Appropriate nutrient intake during this period has a critical role in fetal development [1] and better maternal nutritional status [2]. Failure to receive necessary micro- and macronutrient during this period will result in undernutrition and adverse pregnancy outcome [3]. Undernutrition during pregnancy wields both shortand long-term effects on the health of an infant by programming the infant's development [4], increases the risk of noncommunicable diseases [5], and is intimately related to the survival of both mothers and their babies [6]. Undernourished mothers are more vulnerable to diseases, 


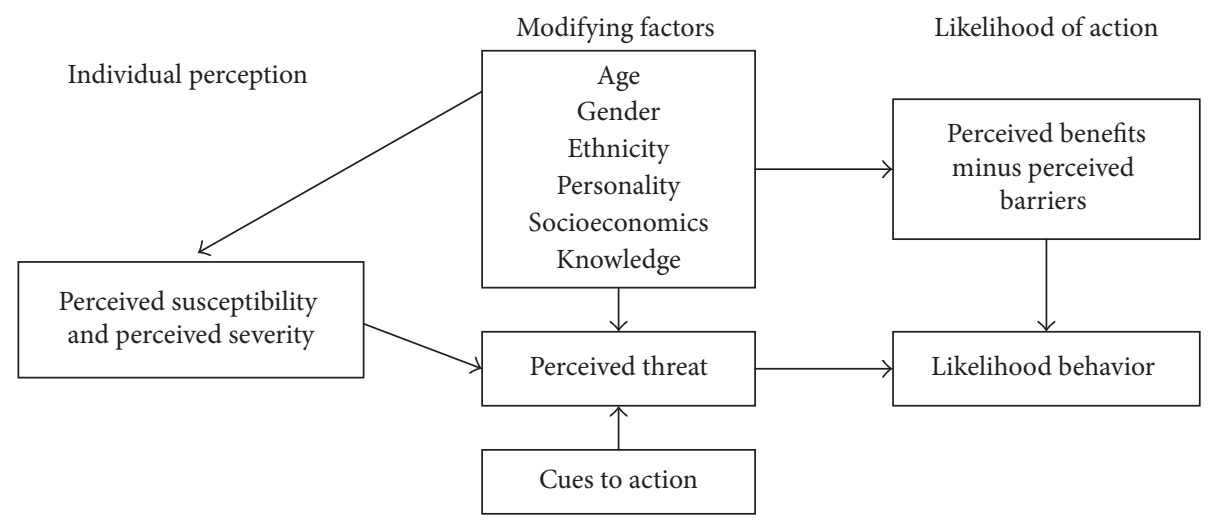

Figure 1: Health Belief Model theory components and linkages.

encounter more miscarriages, and give birth to underweight children whose survival is at risk $[6,7]$.

Ethiopia is one of the countries with high burden of maternal and child undernutrition. Available literatures in Ethiopia indicated that poor dietary practice among pregnant women in Ethiopia ranged from 39.3 to $66.1 \%$ [8-10], and undernutrition was $15.2-35.5 \%$ [9-11]. This might be attributable to poor knowledge and wrong perception towards dietary behaviours. In 2016, 22.4\% of women were undernourished in Ethiopia and 22.9\% in Amhara region, the region where this study was conducted. About $23.6 \%$ of women aged 15-49 are anemic, with $17.8 \%$ having mild anemia, 5\% having moderate anemia, and $0.8 \%$ having severe anemia. The prevalence of anemia in Amhara region was $17.2 \%$ with $14.6 \%$ mild anemia, $2.4 \%$ with moderate anemia, and $0.1 \%$ with severe anemia [12].

Many women in developing countries restrict food intake during pregnancy for different reasons such as to have smaller infants on the premise that smaller infants will carry a lower risk of delivery complications [13] due to cultural influence and premise that it makes fetus big and challenge during delivery $[8,14]$. Restriction of food intake and inappropriate nutrition practices in combination with environmental and socioeconomic factor and infections is common causes of maternal mortality, low birth weight, and intergrowth retardation $[15,16]$. For instance, iodine deficiency causes still birth, cretinism, and mental retardation $[17,18]$, iron deficiency causes anemia and increases the risk of mortality [19], vitamin A deficiency causes night blindness, intrauterine growth retardation, and low birth weight $[20,21]$. Furthermore, low weight gain during pregnancy results in delivery of infants too small for gestational age leading to neonatal mortality and morbidity [22], failure in growth, slow cognitive development, and chronic diseases in adulthood [23].

The world health assembly targeted to reduce under five stunting, anemia in women of reproductive age, and low birth weight by the rate of $40 \%, 29.4 \%$, and $30 \%$ by 2030 , respectively [24]. Without improving nutritional knowledge, dietary practices, and perceived dietary behavior during pregnancy, it may be challenging to achieve this target since optimal physical growth and cognitive development are founded on maternal and child nutrition in the first 1000 days.
The Health Belief Model (HBM) is the most commonly used theory in health education and health promotion to explain change and maintenance of health-related behaviors and as a guiding framework for health behavior interventions [25]. It is a psychological model that attempts to explain and predict health behaviors through focusing on the attitudes and beliefs of individuals. The underlying concept of the HBM is that health behavior is determined by personal beliefs or perceptions about a disease/health condition and the strategies available to decrease its occurrence. It contains several primary constructs/concepts perceived susceptibility, severity, benefit, barrier, and self-efficacy that predict why people will take action to prevent, to screen for, or to control illness conditions (Figure 1) [26].

By using learning methods to counteract and reduce existing barriers, they are able to mitigate these adverse effects. Moreover, people can change their attitudes, and the range of positive behaviors will increase. With this aim, this study was conducted to determine the effect of nutrition education based on Health Belief Model on nutritional knowledge and dietary practice of pregnant women in Dissie town, northeastern Ethiopia, 2017 GC.

\section{Materials and Methods}

2.1. Description of Study Area. This study was conducted in Dissie town, northeast Ethiopia. The town is $401 \mathrm{~km}$ away from Addis Ababa, capital of Ethiopia. According to the Dessie town administration office report of 2017 GC, the town has total population of 216,384 , of which $46.86 \%$ were male and $53.14 \%$ were female. There were 10 subcities and 10 health-care institutions that provide health-care services in the town. Geographically, the town is located at $11^{\circ} 8^{\prime} \mathrm{N}$ latitude and $39^{\circ} 38^{\prime} \mathrm{E}$ longitude with an elevation between $2470 \mathrm{~m}$ and $2550 \mathrm{~m}$ above the sea level. The town mainly characterized by woina-dega climatic condition with annual average temperature $15.2^{\circ} \mathrm{C}$ and $1145 \mathrm{~mm}$ rainfall of the town.

2.2. Study Design and Period. A community-based cluster randomized control trial was employed from May to September 2017 GC. 


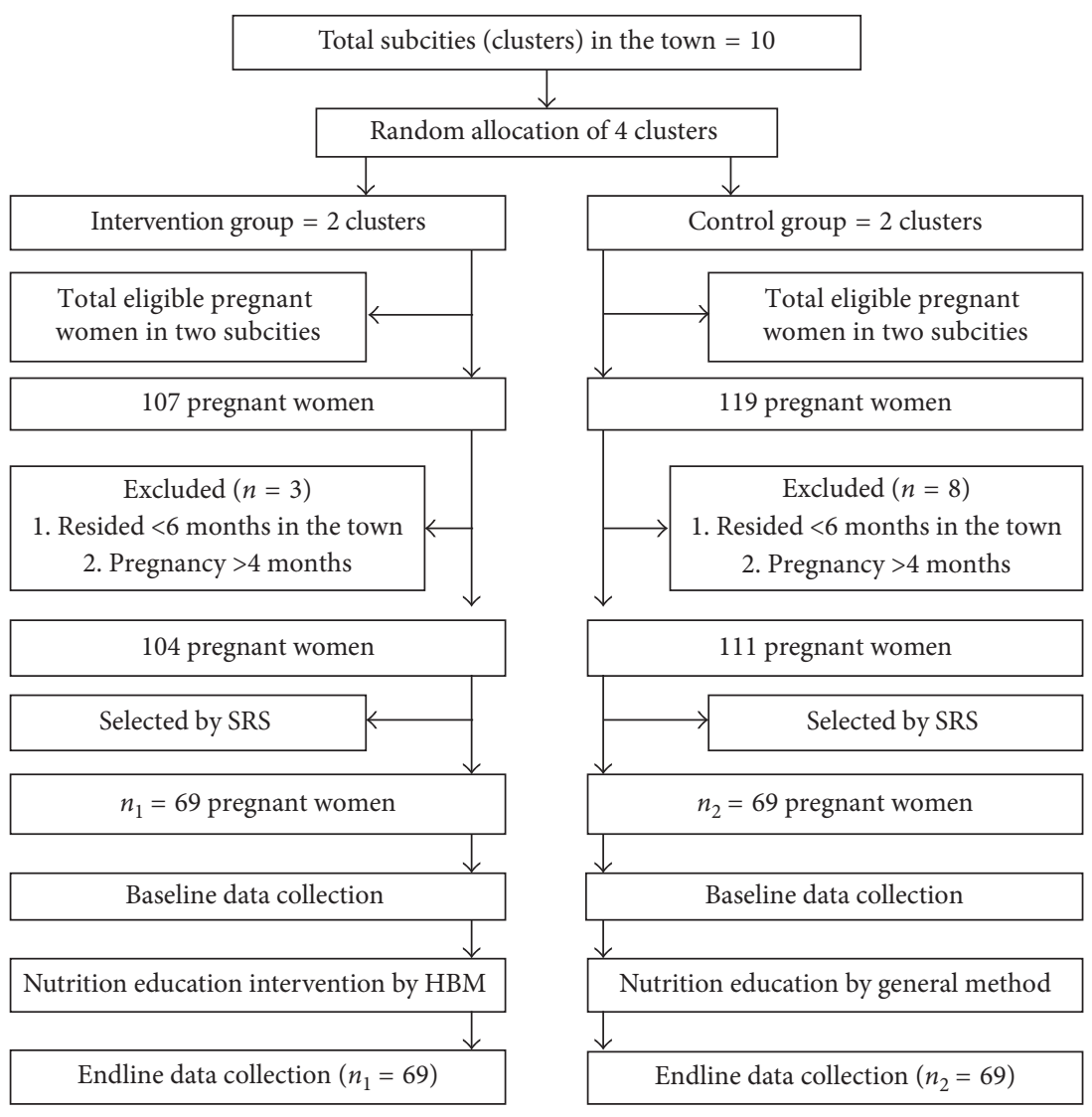

FIGURE 2: Sampling procedure of pregnant women. SRS = simple random sampling; $n_{1}=$ sample size for intervention group; $n_{2}=$ sample size for control group; $\mathrm{HBM}=$ Health Belief Model.

2.3. Source Population. The source population was all pregnant women who were permanent residents in Dissie town during the study period.

2.4. Study Population. The study population was pregnant women who were permanent residents in four selected subcities (clusters) of Dissie town during the study period.

2.5. Inclusion Criteria. All pregnant women who were permanent residents in the town and apparently healthy (self-reported) at the time of baseline data collection were included.

2.6. Exclusion Criteria. Those pregnant women who were above four months of pregnancy at the baseline data collection were excluded.

2.7. Sample Size Determination. The sample size $(n)$ was determined based on the difference between two proportions of dietary practice. The prevalence of good dietary practice $\left(P_{2}=40.1 \%\right)$ was used from previous study [16], for control group. By hypothesizing that the prevalence of good dietary practice would be improved by $25 \%$ in this study, proportion in intervention group $\left(P_{1}\right)$ was $65.1 \%$ $(25 \%+40.1 \%)$. The level of confidence $(\alpha)$ was taken to be
$0.05\left(Z_{\alpha / 2}=1.96\right)$; the power $(1-\beta) 100 \%$ was taken to be $80 \%\left(Z_{2}=0.84\right)$; and $10 \%$ contingency for loss to follow-up was added. Design effect for effect of cluster randomization was ignored because when using design effect, the sample size became higher than study population. Intracluster correlation coefficient (ICC) was calculated to quantify the degree of similarity in the responses of individuals from the same cluster for the primary outcome variables. This gave ICC of 0.132 and -0.024 for dietary practices and nutritional knowledge, respectively. This suggested that clustering was safe to ignore for studied population. Hence, using the following formula, the total final sample size included in this study was 138 (69 for each group) pregnant women:

$$
n=\frac{\left(Z_{1}+Z_{2}\right)^{2} * 2 P(1-P)}{\left(P_{2}-P_{1}\right)^{2}}
$$

2.8. Sampling Technique and Procedure. The sampling procedure is indicated in Figure 2. Pregnant women living in four randomly selected subcities (clusters) were identified from health extension workers' records. Those not registered in health extension records were identified through house to house visit. Sampling frame was created, and participants were selected by simple random sampling method. Random numbers were generated using ENA-for-SMART software. 
2.9. Data Collection Instruments and Procedures. Socioeconomic and demographic information were collected only at baseline. Stage of pregnancy, Health Belief Model constructs, nutrition knowledge, and dietary practices were collected both at baseline and end of nutrition education. Data were collected using structured questionnaires. Nutritional knowledge was collected by using 15 nutrition knowledge questions. Participants were given score $=1$, if they correctly answer knowledge question, and score $=0$, if they did not correctly answer the question. Similarly, dietary practices data were collected by using 17 dietary habit questions. Participants were given score $=1$, if they correctly answer question, favorable or healthy for dietary practice, and score $=0$, if they did not correctly answer the question, not favorable or healthy for dietary practice. Items of Health Belief Model constructs were measured using five-point likert scale (strongly agree $=5$; through strongly disagree $=1$ ). Then, the value of each likert scale scored by participants for each question was summed and the average was calculated.

2.10. Data Quality Control. The questionnaire was first prepared in English, and then translated to local language, Amharic (national language of Ethiopia). Two days of training was given to data collectors and supervisors. Pretesting was done on $5 \%$ of calculated sample size in the area other than study clusters. The data were monitored daily during collection. Collected questionnaires were checked for completeness and consistency during interview and at the end of each day.

2.11. Nutrition Education Intervention. Nutrition education intervention was given to pregnant women between 1 and 4 months at baseline. The education was given every 15 days for 5 consecutive months. For intervention group, education intervention was given based on Health Belief Model theory: (1) susceptibility of the pregnant women and fetus to malnutrition due to inappropriate dietary practices nutrient deficiency or over nutrient intake; (2) severity of malnutrition such as wasting/thinness and overweight/obesity and high risk of fetus to intrauterine growth retardation, brain development, and cognitive function due to macro- and micronutrient deficiency; (3) benefits of right eating or dietary practices on women nutritional status and fetus health, (4) barriers to practice appropriate good dietary practices; and (5) self-confidence/efficacy to follow right dietary practices. The education was provided using theoretical session, poster, brochures, flipchart, and whiteboard.

For the control group, nutrition education was given by trained community health volunteers based on the general usual nutrition education which is currently provided by health extension workers. Education was given at baseline for three consecutive days. Effect of poor nutrition on maternal and child nutritional status and health was clearly explained. The causes of malnutrition were also briefly explained. Moreover, mothers were clearly informed how they can improve dietary practices, nutritional status, and reduce the burden of malnutrition. The educators encouraged pregnant women to grasp knowledge, provide behavioral change through delivering appropriate nutrition information. After providing nutrition education at baseline, five-month follow-up for was done without providing any additional nutrition education.

2.12. Data Processing and Analysis. The questionnaires were coded and entered into SPSS version 20.0. Data were checked for any missing values. Continuous data were checked for normality using the Kolmogrov-Smirnov test. Descriptive statistics such as mean, standard deviation, and percentage were generated. Chi-square test was used to analyze categorized variables. Paired $t$-test for continuous variables and McNemar's test for categorical variables were applied to check significant difference of nutrition knowledge and dietary practice within groups at pre- and postintervention. At 95\% confidence level, value with $P<0.05$ was considered as statistically significant.

\section{Result}

3.1. Sociodemographic and Economic Characteristics of Study Participants. Sociodemographic and economic characteristics of the study participants are depicted in Table 1. A total of 138 (69 in each group) pregnant women were participated. About $48(69.6 \%)$ and $46(66.7 \%)$ of participants were within age range of 26-35 years in intervention group (IG) and control group (CG), respectively. About 58 (84.1\%) and 61 (88.4) of participants were married and living together with their husbands in IG and CG, respectively. About 18 $(26.1 \%)$ in IG and $21(30.4 \%)$ of the participants had no formal education. About 39 (56.5\%) and 33 (47.8\%) of participants had less than four persons per household in IG and CG, respectively. About 14 (20.3\%) of respondents' head of household in IG and $17(24.6 \%)$ in CG were not employed. Regarding with monthly income, 15 (21.7\%) and $20(29.0 \%)$ of participants had monthly income of less than six hindered Ethiopian birr in IG and CG, respectively. About 35 (50.8\%) of participants' cash decision makers were both father and mother in IG while $31(45.0 \%)$ in CG. The chi-square test showed that there was no significance difference $(P>0.05)$ between sociodemographic and economic characteristic of two groups.

The mean and standard deviation (SD) of Health Belief Model (HBM) constructs subscale are shown in Table 2. Except perceiving a barrier, which was decreased, the mean score of all Health Belief Model constructs were increased. The paired $t$-test indicated that there was highly significant difference $(P<0.001)$ between pre- and postnutrition education intervention mean Health Belief Model constructs score in intervention group (IG). The independent $t$-test indicated that there was no significant difference $(P>0.05)$ between mean Health Belief Model construct score of two groups at baseline, but the difference was highly significant $(P<0.001)$ at post nutrition education.

3.2. Nutritional Knowledge of Pregnant Women. The mean and standard deviation (SD) score of nutritional knowledge 
TABle 1: Sociodemographic and economic characteristics of the pregnant women in Dessie town, northeast Ethiopia, 2017 GC $\left(n_{1}=n_{2}=69\right)$.

\begin{tabular}{|c|c|c|c|}
\hline \multirow{2}{*}{ Variables } & \multicolumn{2}{|c|}{$\begin{array}{c}\text { Frequency/percentage, } \\
n(\%)\end{array}$} & \multirow{2}{*}{$\begin{array}{c}P \\
\text { value }\end{array}$} \\
\hline & $\begin{array}{l}\text { Intervention } \\
\text { group }\end{array}$ & $\begin{array}{l}\text { Control } \\
\text { group }\end{array}$ & \\
\hline \multicolumn{4}{|l|}{ Age } \\
\hline 19-25 years & $16(23.1)$ & $21(30.4)$ & \multirow{3}{*}{0.11} \\
\hline 26-35 years & $48(69.6)$ & $46(66.70)$ & \\
\hline$>35$ years & $5(7.2)$ & $2(2.9)$ & \\
\hline \multicolumn{4}{|l|}{ Marital status } \\
\hline Unmarried & $11(15.9)$ & $8(11.6)$ & \multirow{2}{*}{0.29} \\
\hline Married & $58(84.1)$ & $61(88.4)$ & \\
\hline \multicolumn{4}{|l|}{ Ethnicity } \\
\hline Amhara & $42(60.9)$ & $48(69.6)$ & \multirow{4}{*}{0.62} \\
\hline Tigray & $13(18.9)$ & $10(14.5)$ & \\
\hline Afar & $7(10.1)$ & $4(5.8)$ & \\
\hline Others & $7(10.1)$ & $7(10.1)$ & \\
\hline \multicolumn{4}{|l|}{ Religion } \\
\hline Orthodox & $41(59.4)$ & $44(63.8)$ & \multirow{3}{*}{0.98} \\
\hline Muslim & $19(27.5)$ & $18(26.1)$ & \\
\hline Protestant & $9(13.1)$ & $7(10.1)$ & \\
\hline \multicolumn{4}{|c|}{ Head of household } \\
\hline Father & $58(84.1)$ & $61(88.4)$ & \multirow{3}{*}{0.49} \\
\hline Mother & $8(11.6)$ & $4(5.8)$ & \\
\hline Others & $3(4.3)$ & $4(5.8)$ & \\
\hline
\end{tabular}

Educational status of

the participants

No formal education $\quad 18(26.1) \quad 21(30.4)$

Elementary school attended $14(20.3) \quad 13(18.9)$

High school completed $22(31.9) \quad 19(27.5)$

Higher institution completed 15 (21.7) 16 (23.2)

Family income

$<600 \mathrm{ETB} \quad 15(21.7) \quad 20(29.0)$

$\begin{array}{llll}601-1500 \mathrm{ETB} & 26(37.7) & 23(33.3) & 0.69\end{array}$

$>1500 \mathrm{ETB}$

$28(40.6)-26(37.7)$

\begin{tabular}{|c|c|c|c|}
\hline \multicolumn{4}{|l|}{ Cash decision maker } \\
\hline Father alone & $19(27.5)$ & $21(30.4)$ & \multirow{3}{*}{0.19} \\
\hline Mother alone & $15(21.7)$ & $17(24.6)$ & \\
\hline Father and mother & $35(50.8)$ & $31(45.0)$ & \\
\hline \multicolumn{4}{|l|}{ Family size } \\
\hline$\leq 4$ persons & $39(56.5)$ & $33(47.8)$ & \multirow{2}{*}{0.73} \\
\hline$>4$ persons & $30(43.5)$ & $66(52.2)$ & \\
\hline \multicolumn{4}{|l|}{ Household facilities } \\
\hline No radio/television & $7(10.1)$ & $10(14.5)$ & \multirow{2}{*}{0.26} \\
\hline Radio/television & $62(89.9)$ & $59(85.5)$ & \\
\hline \multicolumn{4}{|l|}{$\begin{array}{l}\text { Occupation of the head } \\
\text { of household }\end{array}$} \\
\hline Not employed & $14(20.3)$ & $17(24.6)$ & \multirow{4}{*}{0.84} \\
\hline Government employed & $22(31.9)$ & $21(30.4)$ & \\
\hline Laborer & $9(13.0)$ & $12(17.4)$ & \\
\hline Others & $24(25)$ & $19(27.5)$ & \\
\hline
\end{tabular}

Have source nutrition

information

\begin{tabular}{llll} 
No & $25(36.2)$ & $28(40.6)$ & \multirow{2}{*}{0.56} \\
Yes & $44(63.8)$ & $41(59.4)$ & \\
\hline
\end{tabular}

Health Belief Model constructs score.
TABLE 2: Health Belief Model constructs score of the pregnant women in Dessie town, northeast Ethiopia, 2017 GC $\left(n_{1}=n_{2}=69\right)$.

\begin{tabular}{|c|c|c|c|c|}
\hline \multirow{2}{*}{$\begin{array}{l}\text { HBM } \\
\text { Constructs }\end{array}$} & \multirow{2}{*}{$\begin{array}{l}\text { Study } \\
\text { period }\end{array}$} & \multicolumn{2}{|c|}{ HBM constructs score } & \multirow{2}{*}{$\begin{array}{c}P \\
\text { value* }^{*}\end{array}$} \\
\hline & & $\begin{array}{c}\text { Intervention } \\
\text { group }\end{array}$ & $\begin{array}{l}\text { Control } \\
\text { group }\end{array}$ & \\
\hline \multirow{3}{*}{$\begin{array}{l}\text { Perceived } \\
\text { susceptibility }\end{array}$} & Baseline & $17.9 \pm 4.4$ & $18.5 \pm 4.3$ & 0.29 \\
\hline & Endline & $28.1 \pm 2.1$ & $20.5 \pm 5.6$ & $<0.001$ \\
\hline & $P$ value ${ }^{\mathrm{b}}$ & $<0.001$ & $=0.003$ & \\
\hline \multirow{3}{*}{$\begin{array}{l}\text { Perceived } \\
\text { severity }\end{array}$} & Baseline & $25.2 \pm 6.6$ & $26.7 \pm 6.8$ & 0.20 \\
\hline & Endline & $37.4 \pm 2.6$ & $28.6 \pm 7.8$ & 0.001 \\
\hline & $P$ value ${ }^{\mathrm{b}}$ & $<0.001$ & $=0.05$ & \\
\hline \multirow{3}{*}{$\begin{array}{l}\text { Perceived } \\
\text { benefits }\end{array}$} & Baseline & $19.5 \pm 4.5$ & $18.2 \pm 5.0$ & 0.14 \\
\hline & Endline & $23.6 \pm 1.4$ & $19.2 \pm 5.2$ & 0.001 \\
\hline & $P$ value ${ }^{\mathrm{b}}$ & $<0.001$ & $=0.05$ & \\
\hline \multirow{3}{*}{$\begin{array}{l}\text { Perceived } \\
\text { barriers }\end{array}$} & Baseline & $23.1 \pm 4.7$ & $23.1 \pm 4.5$ & 0.98 \\
\hline & Endline & $16.2 \pm 4.2$ & $21.9 \pm 5.3$ & 0.001 \\
\hline & $P$ value ${ }^{\mathrm{b}}$ & $<0.001$ & $=0.013$ & \\
\hline \multirow{3}{*}{$\begin{array}{l}\text { Perceived } \\
\text { self-efficacy }\end{array}$} & Baseline & $14.8 \pm 3.7$ & $13.7 \pm 4.3$ & 0.10 \\
\hline & Endline & $17.6 \pm 1.9$ & $14.1 \pm 4.1$ & 0.001 \\
\hline & $P$ value ${ }^{\mathrm{b}}$ & $<0.001$ & $=0.285$ & \\
\hline
\end{tabular}

$\mathrm{a}=$ independent $t$-test; $\mathrm{b}=$ paired $t$-test $\mathrm{HBM}=$ Health Belief Model.

are depicted in Table 3. There was no significant difference $(P=0.26)$ between mean nutritional knowledge score of intervention and control groups at baseline, but the difference was highly significant $(P<0.001)$ at the end of nutrition education. The paired $t$-test indicated that the mean nutritional knowledge score was highly significantly improved $(P<0.001)$ from 6.9 to 13.4 in intervention group. Specifically, $100 \%$ of participants in intervention group knew sources of macronutrient- and micronutrient-rich foods and consequences of micronutrient deficiency during pregnancy for both mother herself and fetus at the end of nutrition education. At baseline, there was no significant difference $(P>0.05)$ between nutritional knowledge-related variable of two groups, but the difference was significant $(P<0.05)$ at posttest.

3.3. Dietary Practices of Pregnant Women. The result of dietary practices is shown in Table 4 . The pre- and postintervention good dietary practice was $56.5 \%$ and $84.1 \%$ in intervention group, and $60.9 \%$ and $72.5 \%$ in control group, respectively. Specifically, $50.7 \%$ of participants in IG and $44.9 \%$ in CG experienced food craving at baseline. At the end of intervention, these figures were 28 (40.6) and 26 (37.7\%) in experimental and control group, respectively. At baseline, $30(43.5 \%)$ avoided particular foods particularly due to personal dislike (39.1\%) and at postintervention 32 (46.4\%) avoided due to due to personal dislike (30.4\%) intervention in IG. At baseline, about 38 (55.1\%) participants in IG ate three main meals and at least one additional snack between meals on daily basis. After nutrition education, 52 (75.4\%) of pregnant women ate three meals and at least one additional snack in IG. In control group, 34 (49.3\%) and 45 (65.2\%) of 
TABLE 3: Nutrition knowledge of the pregnant women in Dessie town, northeast Ethiopia, 2017 GC $\left(n_{1}=n_{2}=69\right)$.

\begin{tabular}{|c|c|c|c|c|}
\hline \multirow{2}{*}{ Knowledge variables } & \multirow{2}{*}{ Stud period } & \multicolumn{2}{|c|}{ Frequency and percentage, $n(\%)$} & \multirow{2}{*}{$P$ value } \\
\hline & & Intervention group & Control group & \\
\hline \multirow{2}{*}{ Know balanced diet } & Baseline & $24(34.8)$ & $27(39.1)$ & 0.59 \\
\hline & Endline & $66(95.7)$ & $36(52.2)$ & $<0.001$ \\
\hline \multirow{2}{*}{ Know benefits of balanced diet for fetus and herself } & Baseline & $28(40.6)$ & $31(44.9)$ & 0.61 \\
\hline & Endline & $62(89.9)$ & $38(55.1)$ & $<0.001$ \\
\hline \multirow{2}{*}{$\begin{array}{l}\text { Know dietary source of macronutrient } \\
\text { (protein, carbohydrate, EFA) rich foods }\end{array}$} & Baseline & $54(78.3)$ & $56(81.6)$ & 0.67 \\
\hline & Endline & $69(100)$ & $61(88.4)$ & 0.004 \\
\hline \multirow{2}{*}{$\begin{array}{l}\text { Know dietary sources of micronutrient } \\
\text { (iron, vitamin } A \text {, iodine, vitamin } C \text { ) rich foods }\end{array}$} & Baseline & $22(31.9)$ & $22(31.9)$ & 1.00 \\
\hline & Endline & $69(100)$ & $50(72.5)$ & $<0.001$ \\
\hline \multirow{2}{*}{$\begin{array}{l}\text { Know consequences of micronutrient } \\
\text { deficiency during pregnancy }\end{array}$} & Baseline & $26(33.3)$ & $33(15.9)$ & 0.23 \\
\hline & Endline & $65(100.0)$ & $44(84.1)$ & 0.007 \\
\hline \multirow{2}{*}{ Know appropriate dietary practice } & Baseline & $23(33.3)$ & $32(46.4)$ & 0.08 \\
\hline & Endline & $57(82.6)$ & $33(47.8)$ & $<0.001$ \\
\hline \multirow{3}{*}{ Know synergetic effect of nutrition and infection } & Baseline & $38(55.1)$ & $36(52.2)$ & 0.73 \\
\hline & Endline & $67(97.1)$ & $45(65.2)$ & $<0.001$ \\
\hline & & Mean knowledge sco & & $P$ value $^{\mathrm{a}}$ \\
\hline \multirow{2}{*}{ Mean \pm SD } & Baseline & $6.9 \pm 2.8$ & $7.4 \pm 3.1$ & 0.26 \\
\hline & Endline & $13.4 \pm 3.1$ & $9.8 \pm 3.0$ & $<0.001$ \\
\hline$P$ value ${ }^{b}$ & & $<0.001$ & $=0.001$ & \\
\hline
\end{tabular}

$\mathrm{a}=$ independent $t$-test; $\mathrm{b}=$ paired $t$-test.

pregnant women ate three main meals and at least one additional snack between meals on daily basis at pre- and postintervention, respectively.

About 20 (29\%) of participants in IG skip at least one main meal at baseline which was decreased to $5(7.2 \%)$ at the end of intervention. On the contrary, 22 (31.9\%) and 14 (20.3\%) of participants in CG skipped at least one main meal at baseline and endline, respectively. None of the participants ate fresh fruit on daily basis in both groups at baseline. At postintervention, only $2(2.9 \%)$ ate fresh fruits and vegetables on daily basis in IG but none of the participants in CG. About 37 (53.6\%) of participants in IG added salt nearly at the end cooking food at baseline which was $67(97.1 \%)$ at postintervention. It was $42(60.9 \%)$ at baseline and 55 (79.7\%) at end of the study in CG. At preintervention, about $15(21.7 \%)$ participants followed weight gain in IG and 24 (34.8\%) followed weight gain in CG. At postintervention, 53 (76.8\%) followed weigh gain in IG and 40 (58.0\%) in CG.

The chi-square test showed that there was no significance difference $(P=0.61)$ between dietary practice of two groups at preintervention, but the difference was significant $(P=0.09)$ at postintervention.

\subsection{Correlation of Health Belief Model Construct with} Dietary Knowledge and Dietary Practices. Except perceived self-efficacy, all other HBM constructs showed highly significant correlation $(P<0.001)$ with dietary practices of pregnant women. Perceived susceptibility, severity, and benefits showed significant positive correlation $(P<0.05)$ with nutritional knowledge (Table 5). Perceived benefits showed negative correlation with both dietary practices and nutritional knowledge. Nutritional knowledge was highly significantly positively correlated $(P<0.001)$ with dietary practice.

\section{Discussion}

This study included 138 pregnant women selected from four clusters. The finding supports the effectiveness of nutrition education based on Health Belief Model (HBM) to improve the nutrition knowledge and dietary practices of pregnant women through increasing perceived severity, susceptibility, benefits, self-efficacy, and decreasing perceived barriers. Accordingly, baseline mean nutritional knowledge score of intervention and control group was 6.9 and 7.4, respectively. At postintervention, the figure was significantly increased to 13.4 in intervention group. The preintervention dietary practice in intervention and control group was $56.5 \%$ and $60.9 \%$, respectively. The postintervention result showed that the proportion of pregnant women with good dietary practice increased to $84.1 \%$ in intervention group. The improvement in nutritional knowledge and dietary practice within intervention and between two groups was highly statistically significant $(P<0.001)$ at endline.

The finding of present study was in agreement with other studies [27-30] where they suggested that positive effect of nutrition education nutritional knowledge and dietary habits. Another study from southern Ethiopia indicated that providing nutrition education utilizing HBM significantly improved the level of knowledge and attitude of women on household utilization of pulses in intervention group [31]. Another study from Iran reported that providing nutrition education based on HBM significantly improved knowledge, attitude, and practice relating to calcium intake among adolescent students [32]. Similarly, Tavakoli et al. concluded 
TABLE 4: Dietary practice-related variables among pregnant women in Dessie town, northeast Ethiopia, 2017 GC $\left(n_{1}=n_{2}=69\right)$.

\begin{tabular}{|c|c|c|c|c|}
\hline \multirow{2}{*}{ Variables } & \multicolumn{2}{|c|}{ Intervention group } & \multicolumn{2}{|c|}{ Control group } \\
\hline & Baseline & Endline & Baseline & Endline \\
\hline \multicolumn{5}{|c|}{ Crave food not normally consumed } \\
\hline Yes & $35(50.7)$ & $28(40.6)$ & $31(44.9)$ & $26(37.7)$ \\
\hline \multicolumn{5}{|c|}{ Avoided any food items and reasons for avoidance } \\
\hline Personal dislike & $27(39.1)$ & $21(30.4)$ & $18(26.1)$ & $16(23.2)$ \\
\hline Religion & $3(4.3)$ & $6(8.7)$ & $4(5.8)$ & $4(5.8)$ \\
\hline Makes fetus big & - & $5(7.2)$ & $2(2.9)$ & $1(1.4)$ \\
\hline \multicolumn{5}{|c|}{ Follow specific dietary regime } \\
\hline Yes & $21(30.4)$ & $25(36.2)$ & $29(42.0)$ & $37(53.6)$ \\
\hline \multicolumn{5}{|c|}{$\begin{array}{l}\text { Get } 3 \text { meals per day and at least one snacks } \\
\text { between main meals }\end{array}$} \\
\hline Yes & $38(55.1)$ & $52(75.4)$ & $34(49.3)$ & $45(65.2)$ \\
\hline \multicolumn{5}{|c|}{$\begin{array}{l}\text { Skip any of the following meals during } \\
\text { current pregnancy }\end{array}$} \\
\hline Dinner & $10(14.5)$ & $1(1.4)$ & $11(15.9)$ & $9(13.0)$ \\
\hline Breakfast & $9(13.1)$ & $4(5.8)$ & $9(13.0)$ & $495.8)$ \\
\hline Lunch & $1(1.4)$ & - & $2(2.9)$ & $1(1.4)$ \\
\hline \multicolumn{5}{|c|}{ Eat protein-rich foods on daily basis } \\
\hline Yes & $48(69.6)$ & $64(92.8)$ & $52(75.4)$ & $59(85.5)$ \\
\hline \multicolumn{5}{|c|}{$\begin{array}{l}\text { Habits of eating fresh fruits and vegetables } \\
\text { on daily basis }\end{array}$} \\
\hline Yes & $0(0.0)$ & $2(2.9)$ & $0(0.0)$ & $0(0.0)$ \\
\hline \multicolumn{5}{|c|}{ Use iodized salt and add at the end of cooking } \\
\hline Yes & $37(53.6)$ & $67(97.1)$ & $42(60.9)$ & $55(79.7)$ \\
\hline \multicolumn{5}{|c|}{ Amount of fluid drunk per day } \\
\hline Less than 1.5 liter & $54(78.3)$ & $36(52.2)$ & $50(72.5)$ & $45(65.2)$ \\
\hline More than 1.5 liter & $15(21.7)$ & $33(47.8)$ & $19(27.5)$ & $24(34.8)$ \\
\hline \multicolumn{5}{|c|}{$\begin{array}{l}\text { Include milk, fruit juice, soup, and/or other } \\
\text { nonalcoholic drinks daily }\end{array}$} \\
\hline Yes & $69(100)$ & $69(100)$ & $69(100)$ & $69(100)$ \\
\hline \multicolumn{5}{|c|}{ Follow weight during current pregnancy } \\
\hline Yes & $15(21.7)$ & $53(76.8)$ & $24(34.8)$ & $40(58.0)$ \\
\hline \multicolumn{5}{|c|}{ Drink alcohol during current pregnancy } \\
\hline Yes & $24(34.8)$ & $17(24.6)$ & $24(34.8)$ & $24(34.8)$ \\
\hline \multirow{2}{*}{ Study period } & \multicolumn{4}{|c|}{ Group } \\
\hline & Dietary practice & Intervention & Control & $P$ value \\
\hline \multirow{2}{*}{ Baseline } & Good & $39(56.5)$ & $42(60.9)$ & 0.61 \\
\hline & Poor & $30(43.5)$ & $27(39.1)$ & \\
\hline \multirow{2}{*}{ Endline } & Good & $58(84.1)$ & $50(72.5)$ & 0.09 \\
\hline & Poor & $11(15.9)$ & $19(27.5)$ & \\
\hline
\end{tabular}

that nutrition education based on HBM has positive significant effect of mean knowledge score, attitude, and behavior in medical student [33]. The finding was also in agreement with another study from Iran in which the authors suggested that providing education based on the Health Belief Model (HBM) can effectively improve the knowledge, attitude, and practice of adolescent students towards nutrient intake. Moreover, educational interventions based on health promotion patterns can be effective in enhancing awareness, better understanding of risks and reducing barriers to healthy behavior, and, ultimately, improving women's health and nutritional performance during pregnancy [34]. Sharifirad et al. also indicated the positive outcome of nutrition education intervention by comparing the effect of nutritional education program based on HBM with traditional education recommended weight gain among pregnant women in Gonabad [35].

The high improvement of nutritional knowledge might be due to frequent education and follow-up during intervention period as well as short interval between the preand postassessment. Moreover, the improvement might be explained by increased understanding of the perceived risk and severity of inappropriate nutrition and perceived benefits of practicing good nutrition during pregnancy. On the contrary, the higher improvement of dietary practice intervention group might be explained by higher impact of Health Belief Models by increasing perceived susceptibility, severity, benefits, self-efficacy, and decreased perceived 
TABLE 5: Correlation of Health Belief Model constructs with dietary practice and nutritional knowledge of pregnant women in Dessie town, northeast Ethiopia, 2017 GC $\left(n_{1}=n_{2}=69\right)$.

\begin{tabular}{|c|c|c|c|c|c|c|c|}
\hline Variables & $\begin{array}{c}\text { Perceived } \\
\text { susceptibility }\end{array}$ & $\begin{array}{c}\text { Perceived } \\
\text { severity }\end{array}$ & $\begin{array}{c}\text { Perceived } \\
\text { benefits }\end{array}$ & $\begin{array}{c}\text { Perceived } \\
\text { barriers }\end{array}$ & $\begin{array}{c}\text { Perceived } \\
\text { self-efficacy }\end{array}$ & $\begin{array}{l}\text { Dietary } \\
\text { practice }\end{array}$ & $\begin{array}{l}\text { Nutritional } \\
\text { knowledge }\end{array}$ \\
\hline $\begin{array}{l}\text { Perceived } \\
\text { susceptibility }\end{array}$ & 1 & & & & & & \\
\hline Perceived severity & $\begin{array}{c}0.900 \\
P<0.001\end{array}$ & 1 & & & & & \\
\hline Perceived benefits & $\begin{array}{c}0.741 \\
P<0.001\end{array}$ & $\begin{array}{c}0.657 \\
P<0.001\end{array}$ & 1 & & & & \\
\hline Perceived barriers & $\begin{array}{c}-0.795 \\
P<0.001\end{array}$ & $\begin{array}{c}-0.687 \\
P<0.001\end{array}$ & $\begin{array}{c}0.770 \\
P<0.001\end{array}$ & 1 & & & \\
\hline $\begin{array}{l}\text { Perceived } \\
\text { self-efficacy }\end{array}$ & $\begin{array}{c}0.628 \\
P<0.001\end{array}$ & $\begin{array}{c}0.628 \\
P<0.001\end{array}$ & $\begin{array}{c}0.919 \\
P<0.001\end{array}$ & $\begin{array}{c}-0.601 \\
P<0.001\end{array}$ & 1 & & \\
\hline Dietary practice & $\begin{array}{c}0.588 \\
P<0.001\end{array}$ & $\begin{array}{c}0.608 \\
P<0.001\end{array}$ & $\begin{array}{c}0.342 \\
P<0.001\end{array}$ & $\begin{array}{c}-0.412 \\
P<0.001\end{array}$ & $\begin{array}{c}0.253 \\
P=0.36\end{array}$ & 1 & \\
\hline $\begin{array}{l}\text { Nutritional } \\
\text { knowledge }\end{array}$ & $\begin{array}{c}0.427 \\
P<0.001\end{array}$ & $\begin{array}{c}0.424 \\
P<0.001\end{array}$ & $\begin{array}{c}0.214 \\
P=0.077\end{array}$ & $\begin{array}{c}-0.300 \\
P=0.012\end{array}$ & $\begin{array}{c}0.149 \\
P=0.221\end{array}$ & $\begin{array}{c}0.419 \\
P<0.001\end{array}$ & 1 \\
\hline
\end{tabular}

barriers to practice appropriate nutrition and improvement in nutritional knowledge. Women, who fear for severity of malnutrition, understand the benefits of practicing good nutrition for both fetus and herself, and have ability to act on good nutritional activities, were more likely to practice good nutrition. Similarly, women exposed to nutrition information could follow good nutrition practices since research evidence suggested that those women exposed to nutrition information were more likely to practice good dietary practices [36]. Knowledge on severity and susceptibility of mother herself and fetus to malnutrition and poor health outcomes increases; they are likely to be more sensitive to the health of their fetus and infant and follow dietary pattern modifications. On the contrary, improved dietary practice might be explained by improved nutritional knowledge since positive significant correlation was observed with dietary practices.

The slight improvement in nutritional knowledge and dietary practices of control group over time might be due to provision of three-day nutrition education at baseline so that participants practiced as delivered nutrition education information. In addition, currently the health extension workers are delivering basic nutrition counseling while pregnant women attend antenatal care.

This study revealed that except perceived barriers which were decreased, all the other mean Health Belief Model scores significantly increased after nutrition education in experimental group. The perceived barriers were decreased in this study. Apart from perceived barriers, the result of other Health Belief Model constructs' scores was in agreement with finding from Iran [33]. The perceived barriers were increased in compared study. The difference on perceived barriers of two studies might be due to variation in culture, socioeconomic status, and demographic characteristics of two participants. The perceived HBM constructs' scores were in line with other studies [28, 30-33].

Perceived susceptibility and severity showed strong significant correlation $(P<0.001)$, perceived barriers were moderately correlated $(P<0.001)$, and perceived benefits were weakly correlated with dietary practices of pregnant women. This suggested that even if other constructs showed significant correlation, perceived susceptibility and severity have more effect on improving the dietary practices. The negative correlation of perceived barriers with dietary practices indicates that providing nutrition education has a power to improve dietary practices by decreasing barriers for good dietary behaviours. Perceived susceptibility and severity showed moderate significant correlation indicating that they have better effect of improving nutritional knowledge compared to other HBM constructs. The significant correlation of perceived severity and barriers with dietary practices and perceived susceptibility and barriers to nutritional knowledge was in line with a study done Iran [33].

\section{Conclusion}

The overall result indicated that the nutritional knowledge and dietary practices of the pregnant women in intervention group were highly improved compared to their counterparts as well as preintervention results. Hence, delivering nutrition education based on Heath Belief Model can be appropriate tool to improve nutritional knowledge, perceived dietary behaviours, and dietary practice of pregnant women.

\section{Recommendations}

The governmental, nongovernmental organization, health extension workers, and other health-care providers should include Health Belief Model construct into existing nutrition education programs. Moreover, the government should include Health Belief Model constructs in national nutrition education guidelines to bring change in nutritional knowledge and dietary practices of pregnant women.

\section{Data Availability}

Datasets used and/or analyzed during the current study are available from the corresponding author on reasonable request. 


\section{Ethical Approval}

Ethical approval was obtained from Wollo University Ethical Review Committee. The letter was written from Wollo University Research and Community Service Office to Dessie Town Health Department. Finally, permission was obtained from Dessie Town Health Department.

\section{Consent}

Written consent was obtained from each study participant in selected clusters.

\section{Conflicts of Interest}

The authors declare that they have no conflicts of interest.

\section{Authors' Contributions}

Tona Zema Diddana drafted study design, carried out data collection, data management, data analysis, and interpretation, and drafted the manuscript. Gezahegn Nigusse Kelkay participated in data analysis and interpretation and revised the drafted manuscript. Amanuel Nana Dola participated in data analysis and interpretation and revised the drafted manuscript. Abinet Arega Sadore participated in the study design and revised the drafted manuscript. All authors read and approved the final manuscript.

\section{Acknowledgments}

The researchers gratefully thank Wollo University for funding this research. The authors would also like to thank Dessie town administration and health department for allowing them to conduct this research in the community. Finally, the authors highly acknowledge their study participants for providing all necessary information and data collectors.

\section{References}

[1] Y. Cheng, M. J. Dibley, X. Zhang, L. Zeng, and H. Yan, "Assessment of dietary intake among pregnant women in a rural area of western China," BMC Public Health, vol. 9, no. 1, p. 222, 2009.

[2] C. E. Ey, M. S. Zalilah, C. Y. Ys, and S. Norhasmah, "Dietary diversity is associated with nutritional status of Orang Asli children in Krau Wildlife Reserve, Pahang," Malaysian Journal of Nutrition, vol. 18, no. 1, pp. 1-13, 2012.

[3] Z. A. Bhutta, J. K. Das, A. Rizvi et al., "Evidence-based interventions for improvement of maternal and child nutrition: what can be done and at what cost?," The Lancet, vol. 382, no. 9890, pp. 452-477, 2013.

[4] E. Isolauri, "Diet, nutrition and nutritional status: from the mother to the infant," Nest, vol. 31, pp. 2-3, 2011.

[5] B. Koletzko, B. Brands, L. Poston et al., "Early nutrition programming of long-term health," Proceedings of the Nutrition Society, vol. 71, no. 3, pp. 371-378, 2012.

[6] R. E. Black, L. H. Allen, Z. A. Bhutta et al., "Maternal and child undernutrition: Global and regional exposures and health consequences," The Lancet, vol. 371, no. 9608, pp. 243-260, 2008.
[7] ACC/SCN, "Symposium report on a nutrition policy discussion paper on women and nutrition," Geneva, vol. 6, pp. 27-31, 1990.

[8] G. Daba, F. Beyene, H. Fekadu, and W. Garoma, "Assessment of nutritional practices of pregnant mothers on maternal nutrition and associated factors in Guto Gida Woreda, East Wollega Zone, Ethiopia," Science, Technology and Arts Research Journal, vol. 2, no. 3, pp. 105-113, 2013.

[9] A. Nana, R. P. C. J. Prasad, and T. Zema, "Dietary practices, nutritional status and associated factors among pregnant women in Bahirdar town, Northwest Ethiopia," M.Sc. thesis, Bahir Dar Univerisity, Bahir Dar, Ethiopia, 2016.

[10] D. Kuche, P. Singh, D. Moges, and T. Belachew, "Nutritional status and associated factors among pregnant women in Wondo Genet District, Southern Ethiopia," Journal of Food Science and Engineering, vol. 5, no. 2, pp. 85-94, 2015.

[11] M. Moges, A. Worku, and E. Loha, "Nutritional status and associated factors among pregnant women in Boricha Woreda, Sidama Zone, Southern Ethiopia," European Journal of Nutrition \& Food Safety, vol. 5, no. 5, pp. 2347-5641, 2015.

[12] Central Statistical Agency (Ethiopia) and ICF International, Ethiopia Demographic and Health Survey 2016, Central Statistical Agency and ORC Macro, Addis Ababa, Ethiopia and Calverton, MD, USA, 2017.

[13] D. Kuche, P. Singh, and D. Moges, "Dietary practices and associated factors among pregnant women in Wondo Genet District, Southern Ethiopia," Journal of Pharmaceutical and Scientific Innovation, vol. 4, no. 5, pp. 270-275, 2015.

[14] M. Tena and J Bacalo, "Malnutrition and poverty," Annual Review of Nutrition, vol. 22, pp. 241-253, 2002.

[15] L. H. Madhavi and H. K. G. Singh, "Nutritional status of rural pregnant women," People's Journal of Scientific Research, vol. 4 , no. 2, pp. 20-23, 2011.

[16] M. S. Alemayehu and E. M. Tesema, "Dietary practice and associated factors among pregnant women in Gondar Town North West, Ethiopia, 2014," International Journal of $\mathrm{Nu}$ trition and Food Sciences, vol. 4, no. 6, pp. 707-712, 2015.

[17] H. C. Chasi, "Infant mortality and weight at birth: 1960 United Stated weight cohort," American Journal of Public Health, vol. 59, p. 1618, 1969.

[18] P. O. D. Pharoah, "Endemic cretinism in the Jimi Valley of New Guinea", Ph.D. thesis, London University, London, UK, 1971.

[19] F. Delange, "Administration of iodized oil during pregnancy: a summary of the published evidence," Bulletin of the World Health Organization, vol. 74, no. 1, pp. 101-108, 1996.

[20] T. H. Bothwell, "Iron requirements in pregnancy and strategies to meet them," American Journal of Clinical Nutrition, vol. 72, no. 1, pp. 257S-264S, 2000.

[21] J. Katz, S. K. Khatry, K. P. West et al., "Night blindness is prevalent during pregnancy and lactation in rural Nepal," Journal of Nutrition, vol. 125, no. 8, pp. 2122-2127, 1995.

[22] P. Christian, K. P. West, S. K. Khartry et al., "Night blindness of pregnancy in rural Nepal: nutritional and health risks," Int $J$ Epidemiol, vol. 27, no. 2, pp. 231-237, 1998.

[23] M. S. Kramer, "Determinants of low birth weight: methodological assessment and meta-analysis," Bulletin of the World Health Organization, vol. 65, no. 5, pp. 663-737, 1987.

[24] F. Branca, L. Grummer-Strawn, E. Borghi, M. de Blössner, and M. Onis, "Extension of the WHO maternal, infant, and young child nutrition targets to 2030," SCN News, vol. 41, pp. 55-58, 2015.

[25] K. K. Saha, E. A. Frongillo, D. S. Alam, S. E. Arifeen, A. K. Persson, and K. M. Rasmussen, "Appropriate infant feeding practices result in better growth of infants and young 
children in rural Bangladesh," American Journal of Clinical Nutrition, vol. 87, no. 6, pp. 1852-1859, 2008.

[26] V. Stretcher and I. M. Rosenstock, "Health belief model," in Health Behaviour And Health Education: Theory, Research and Practice, K. Glanz, F. M. Lewis, and B. K. Rimer, Eds., Jossey-Bass, San Francisco, CA, USA, 2nd edition, 1997.

[27] Rosa Dansa, Susan J. Whiting, and Fiekadu Reta, Effects of Nutrition Education on Pulses Consumption and Nutritional Status of Adolescent Girls, Unpublished M.Sc. thesis, Huletegna Choroko School, Halaba Special District, and Southern Ethiopia, Hawassa, Ethiopia, 2016.

[28] A. Zelalem, M. Endeshaw, M. Ayenew, S. Shiferaw, and R. Yirgu, "Effect of nutrition education on pregnancy specific nutrition knowledge and healthy dietary practice among pregnant women in Addis Ababa," Clinics in Mother and Child Health, vol. 14, no. 3, p. 265, 2017.

[29] T. Befikadu, J. H. Susan, M. Demmelash, and S. Pragya, "Application of the health belief model to teach complementary feeding messages in Ethiopia," Ecology of Food and Nutrition, vol. 54, no. 5, pp. 572-582, 2015.

[30] M. Demmelash, J. H. Carol, B. Getenesh, and J. W. Susan, "The effectiveness of nutrition education: applying the Health Belief Model in child-feeding practices to use pulses for complementary feeding in Southern Ethiopia," Journal Ecology of Food and Nutrition, vol. 55, no. 3, pp. 308-323, 2016.

[31] M. Yetnayet, C. J. Henry, G. Berhanu, S. J. Whiting, and N. Regassa, "Nutrition education promoted consumption of pulse based foods among rural women of reproductive age in Sidama Zone, Southern Ethiopia," African Journal of Food, Agriculture, Nutrition and Development, vol. 17, no. 3, pp. 12377-12395, 2017.

[32] M. Naghashpour, G. Shakerinejad, M. R. Lourizadeh, S. Hajinajaf, and F. Jarvandi, "Nutrition Education based on health belief model improves dietary calcium intake among female students of junior high schools," Journal of Health Population Nutrition, vol. 32, no. 3, pp. 420-429, 2014.

[33] H. R. Tavakoli, H. Dini-Talatappeh, F. Rahmati-Najarkolaei, and M. G. Fesharaki, "Efficacy of HBM-based dietary education intervention on knowledge, attitude, and behavior in medical students," Iranian Red Crescent Medical Journal, vol. 18, no. 11, article e23584, 2016.

[34] S. E. Lee, S. A. Talegawkar, M. Merialdi, and L. E. Caulfield, "Dietary intakes of women during pregnancy in low- and middle-income countries," Public Health Nutrition, vol. 16, no. 8, pp. 1340-1353, 2013.

[35] G. R. Sharifirad, A. Tol, S. Mohebi, M. Matlabi, H. Shahnazi, and M. Shahsiah, "The effectiveness of nutrition education program based on health belief model compared with traditional training," Journal of Education and Health Promotion, vol. 2, no. 15, 2013.

[36] M. T. Ruel, "Operationalizing dietary diversity: a review of measurement issues and research priorities," Journal of $\mathrm{Nu}$ trition, vol. 133, no. 11, pp. 3911S-3926S, 2003. 


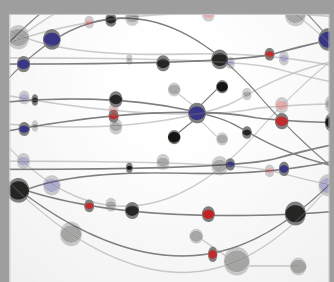

The Scientific World Journal
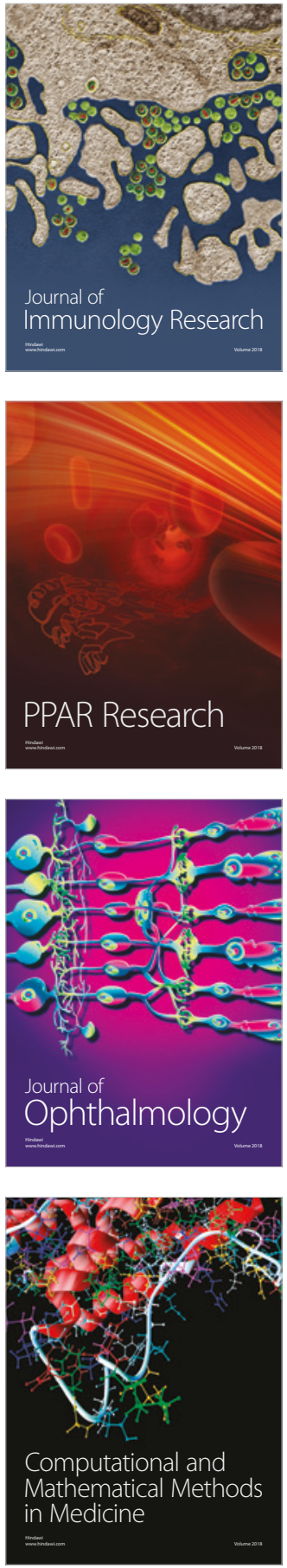

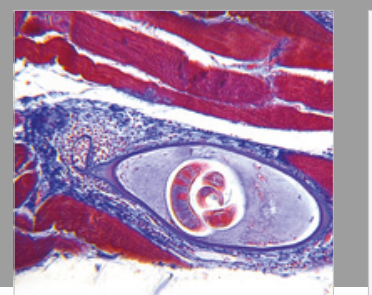

Gastroenterology Research and Practice

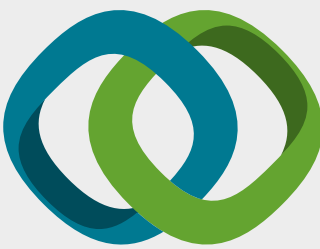

\section{Hindawi}

Submit your manuscripts at

www.hindawi.com
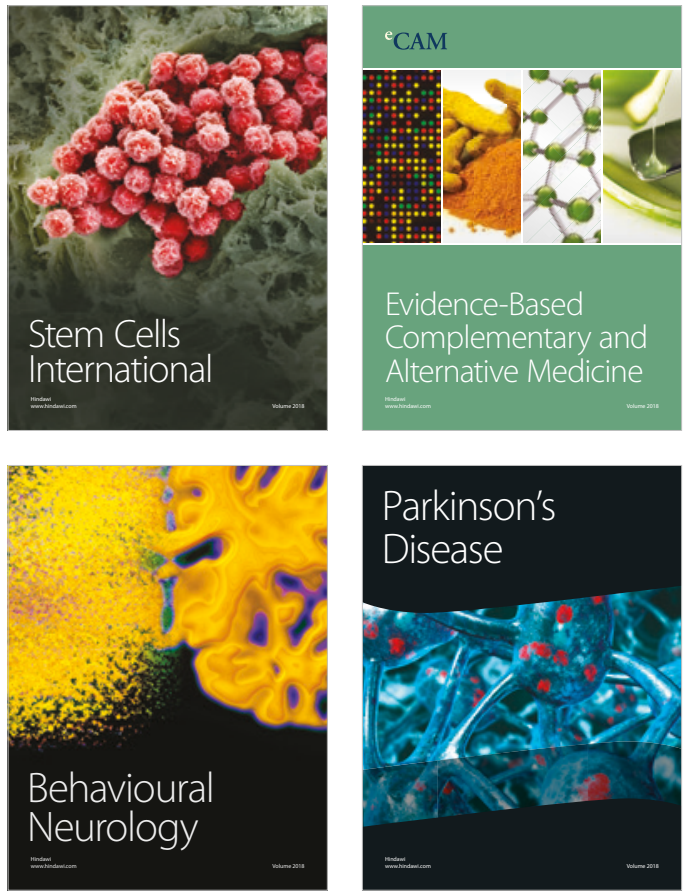

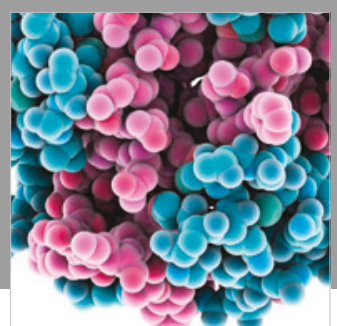

ournal of

Diabetes Research

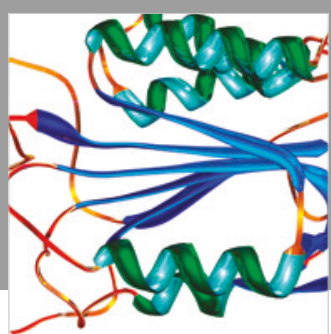

Disease Markers
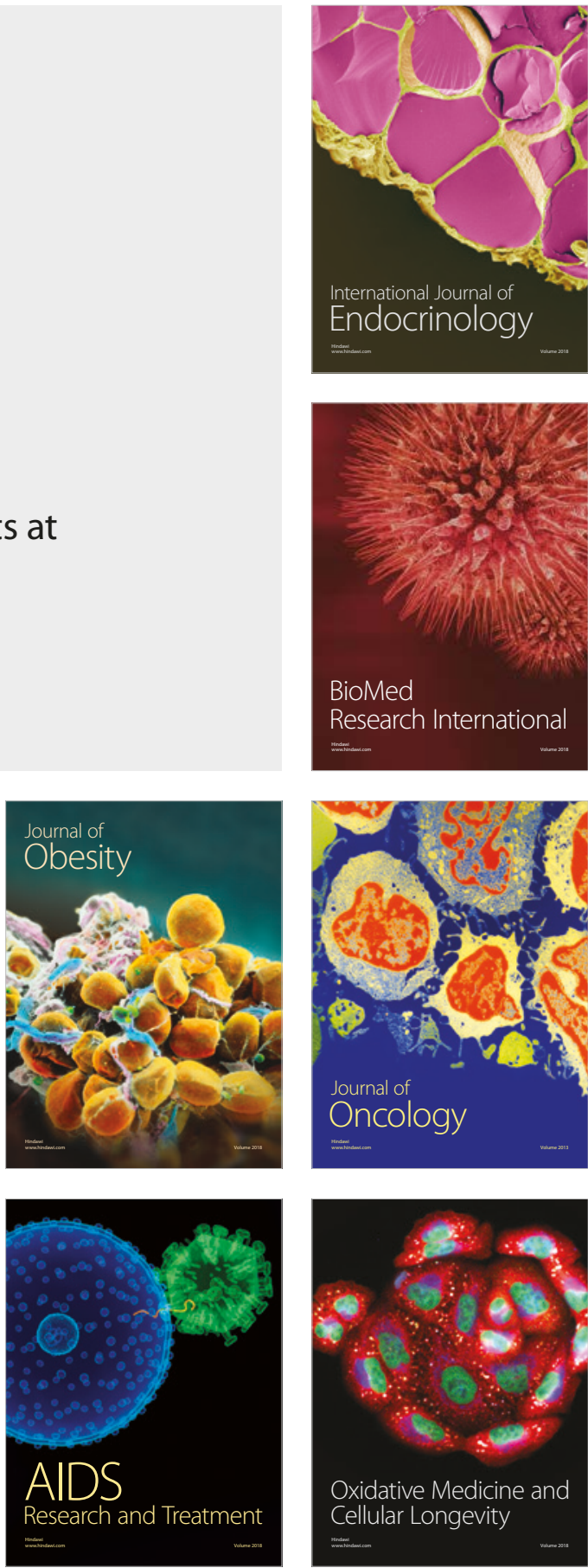